\title{
Erosão hídrica em solos cultivados e sob mata ciliar
}

\author{
Renata Santos Momoli(1) e Miguel Cooper ${ }^{(2)}$ \\ (1)Universidade Federal de Goiás, Instituto de Estudos Socioambientais IESA, Campus II Samambaia, Caixa Postal 131, CEP 74001-970, \\ Goiânia, GO, Brasil. E-mail: rsmomoli@gmail.com ${ }^{(2)}$ Universidade de São Paulo, Escola Superior de Agricultura Luiz de Queiróz, Departamento \\ de Ciência do Solo, CEP 13400-000 Piracicaba, SP, Brasil. E-mail: mcooper@usp.br
}

Resumo - O objetivo deste trabalho foi identificar atributos dos solos e de sedimentos como instrumentos para determinação dos impactos decorrentes da erosão hídrica, bem como propor redução do sobreúso dos solos no Cerrado goiano. Solos e sedimentos da mata ciliar do Córrego Ponte Nova, bem como do cultivo de soja a montante foram avaliados por micromorfometria quanto à morfologia, à granulometria e à porosidade. $\mathrm{Na}$ encosta cultivada, o solo foi classificado como Latossolo Vermelho distroférrico, e, na mata ciliar de vereda, como Plintossolo Pétrico Concrecionário êutrico e Gleissolo Melânico Tb distrófico típico. Solos e sedimentos foram predominantemente argilosos, e a fração argila encontrava-se naturalmente agregada em partículas maiores, de tamanho silte e areia. Análises morfológicas, granulométricas e de porosidade, por micromorfometria, possibilitaram distinguir os sedimentos dos solos soterrados, pela diferenciação de coloração, textura e porosidade. Elevada concentração de agregados de argila tamanho areia no Gleissolo Melânico sugere a remoção seletiva de partículas finas, o que indica erosão no solo sob a mata ciliar. A elevada deposição de sedimentos sobre os solos da mata ciliar compromete a função de filtro do solo e também a perpetuidade e a regeneração da floresta por causa do soterramento de sementes e plântulas.

Termos para indexação: erosão, impactos ambientais, micromorfometria, planejamento agrícola, sedimentos.

\section{Water erosion on cultivated soil and soil under riparian forest}

\begin{abstract}
The objective of this work was to identify attributes of soil and of sediments as a tool to determine the impacts from water erosion, as well as to propose reducing the overuse of the soil in the Cerrado, in the state of Goiás, Brazil. Soils and sediments from the riparian forest of the Ponte Nova Stream and from upstream soybean crop areas were evaluated by micromorphometrics as to morphology, particle size, and porosity. Rhodic Oxisol was present in the cultivated hillside, and Petroferric Oxisol and Typic Eutraquox, in the riparian forest path. Soils and sediments were predominantly clayed, and the clay fraction was naturally aggregated into larger particles of silt and sand sizes. Analyses of morphological atributes, particle size, and porosity - by micromorphometrics - allowed to distinguish the sediment of buried soils by color, texture, and porosity differentiation. The high concentration of sandy-sized clay aggregates in Typic Eutraquox suggests the selective removal of fine particles, indicating soil erosion under the riparian forest. The high sediment deposition on the riparian forest soils is a risk to the soil filter function, and also to the perpetuity and regeneration of the forest because of the burial of seeds and seedlings.
\end{abstract}

Index terms: erosion, environmental impacts, micromorphometry, agricultural planning, sediments.

\section{Introdução}

Solos historicamente submetidos a cultivos sucessivos, nos Estados do Paraná e São Paulo, Brasil, apresentam prejuízos causados pela erosão estimados em 242 e 212 milhões de dólares ao ano, respectivamente (Telles et al., 2011). Os solos do Cerrado, apesar da sua recente ocupação, vêm sofrendo expressiva degradação em decorrência da intensificação do uso nas últimas quatro décadas (Momoli et al., 2012). Impactos locais, como erosão e compactação dos solos, uma vez instalados, dão origem a impactos associados em áreas à jusante, como poluição e assoreamento dos corpos hídricos (Lal, 2014).

A taxa média de erosão do solo avançou de 2,4 para 2,6 Mg ha ${ }^{-1}$ ano $^{-1}$ em Latossolos do Cerrado no Estado de Minas Gerais, segundo estimativas que consideraram as alterações de uso do solo no período entre 1986 e 2011 (Olivetti et al., 2015). Apesar de reconhecidos como solos de baixa erodibilidade, os Latossolos cultivados apresentaram perdas de solo de até $67,24 \mathrm{Mg} \mathrm{ha}^{-1} \mathrm{ano}^{-1} \mathrm{em}$ condições de ausência de cobertura vegetal, cinco vezes acima do limite máximo de tolerância, 12,7 Mg ha-1 ano $^{-1}$ (Carvalho et al., 2007). 
A erosão hídrica pode refletir uso e manejo inadequados do solo, que promovem redução na porosidade e alteração do balanço infiltração/ escoamento de água. A passagem de máquinas agrícolas, por exemplo, promove a compactação do solo e favorece a formação de erosão concentrada em Latossolos (Thomaz, 2013). Operações mecanizadas realizadas sobre Latossolo Vermelho distroférrico promoveram deformações nos solos cultivados e resultaram em redução da conectividade entre os poros (Silva et al., 2015).

Aspectos da macro e mesoporosidade do solo - tais como porosidade total, tamanho e forma dos poros - podem ser investigados utilizando-se análise de imagens (micromorfometria). Esta análise apresenta elevada eficiência quando comparada às análises de densidade do solo, porosidade total, macro e microporosidade, resistência do solo à penetração e condutividade hidráulica do solo saturado (Souza et al., 2006).

Enquanto a erosão de solos cultivados tem sido exaustivamente investigada, as consequências relacionadas ao acúmulo de sedimentos sobre os solos úmidos à jusante ainda carecem de estudos aprofundados. Solos de áreas úmidas, como veredas, podem apresentar importantes alterações quanto à textura e porosidade em razão da sedimentação proveniente da erosão à montante. Tais alterações podem representar graves impactos à qualidade do solo e da água, pois localizam-se em áreas destinadas à preservação permanente (APP).

A identificação da extensão e do alcance das alterações provocadas pela erosão dos solos agrícolas pode contribuir para a redefinição da largura ótima de mata ciliar nas APPs de beira de rios e de nascentes, que consta no Novo Código Florestal, conforme Lei $\mathrm{n}^{ }$ 12.651/12. Áreas Hidrologicamente Sensíveis (AHS) podem ser utilizadas na proposição de delimitação de APPs, desde que haja indicadores de alta sensibilidade hidrológica disponíveis para serem adotados (Siefert \& Santos, 2012).

A avaliação de atributos como morfologia, distribuição granulométrica e porosidade por micromorfometria dos solos sob mata ciliar e sob cultivo podem ser utilizados como instrumentos hidrogeomorfopedológicos, para a identificação das causas e consequências de impactos associados à erosão, e para delimitação da largura ótima de mata ciliar.

O objetivo deste trabalho foi identificar atributos dos solos e de sedimentos como instrumentos para determinação dos impactos decorrentes da erosão hídrica, bem como propor redução do sobreúso dos solos no Cerrado goiano.

\section{Material e Métodos}

Este estudo foi realizado em ambiente de vereda, no qual se encontram diversas nascentes do Córrego Ponte Nova, afluente do Rio Meia Ponte, no município de Goiatuba, GO, entre as coordenadas UTM 666254,51 e $8008387,21 \mathrm{~m}$ da Zona 22S, Datum WGS1984 (Figura 1).

O relevo da região divide-se em três grandes superfícies geomórficas: i) SRAIV - Superfície Regional de Aplainamento entre cotas médias de 400 a $550 \mathrm{~m}$ de altitude e dissecação média; ii) SRAIISuperfície Regional de Aplainamento entre as cotas 800 a $1.000 \mathrm{~m}$, associada aos Relevos Tabulares na Bacia do Rio Paraná com fraca dissecação e; iii) ZER - Zona de Erosão Recuante, correspondente às escarpas íngremes que tangenciam as duas superfícies aplainadas (Latrubesse \& Carvalho, 2006) (Figura 2).

Quanto à geologia, predominam os basaltos e diques de diabásio da Formação Serra Geral intertrapeados aos sedimentos da Formação Botucatu e sedimentos Terciários (Coberturas Detrito-Lateríticas, TQdl) da Bacia do Rio Paraná.

Regionalmente, os solos distribuem-se em Latossolos Vermelhos distroférricos nas áreas aplainadas da SRAII e SRAIV entre 400 a $550 \mathrm{~m}$ e 800 a $1.000 \mathrm{~m}$ de altitude; Nitossolos, Argissolos e Cambissolos nas encostas de relevo ondulado e forte ondulado, entre 550 a $800 \mathrm{~m}$ de altitude; Gleissolos e Neossolos Flúvicos nas baixadas úmidas correspondentes às zonas ripárias, sujeitas às inundações periódicas, e Plintossolos Pétricos relacionados aos locais com exposição das couraças lateríticas com drenagem imperfeita a impedida (Galinkin, 2003; Santos et al., 2013).

O clima da região é caracterizado como tropical quente e úmido, do tipo Aw, segundo classificação de Köppen, com duas estações climáticas bem definidas. O período chuvoso ocorre entre os meses de outubro e abril, e o período seco, de maio a setembro, com precipitação pluviométrica média anual de $1.500 \mathrm{~mm}$. 


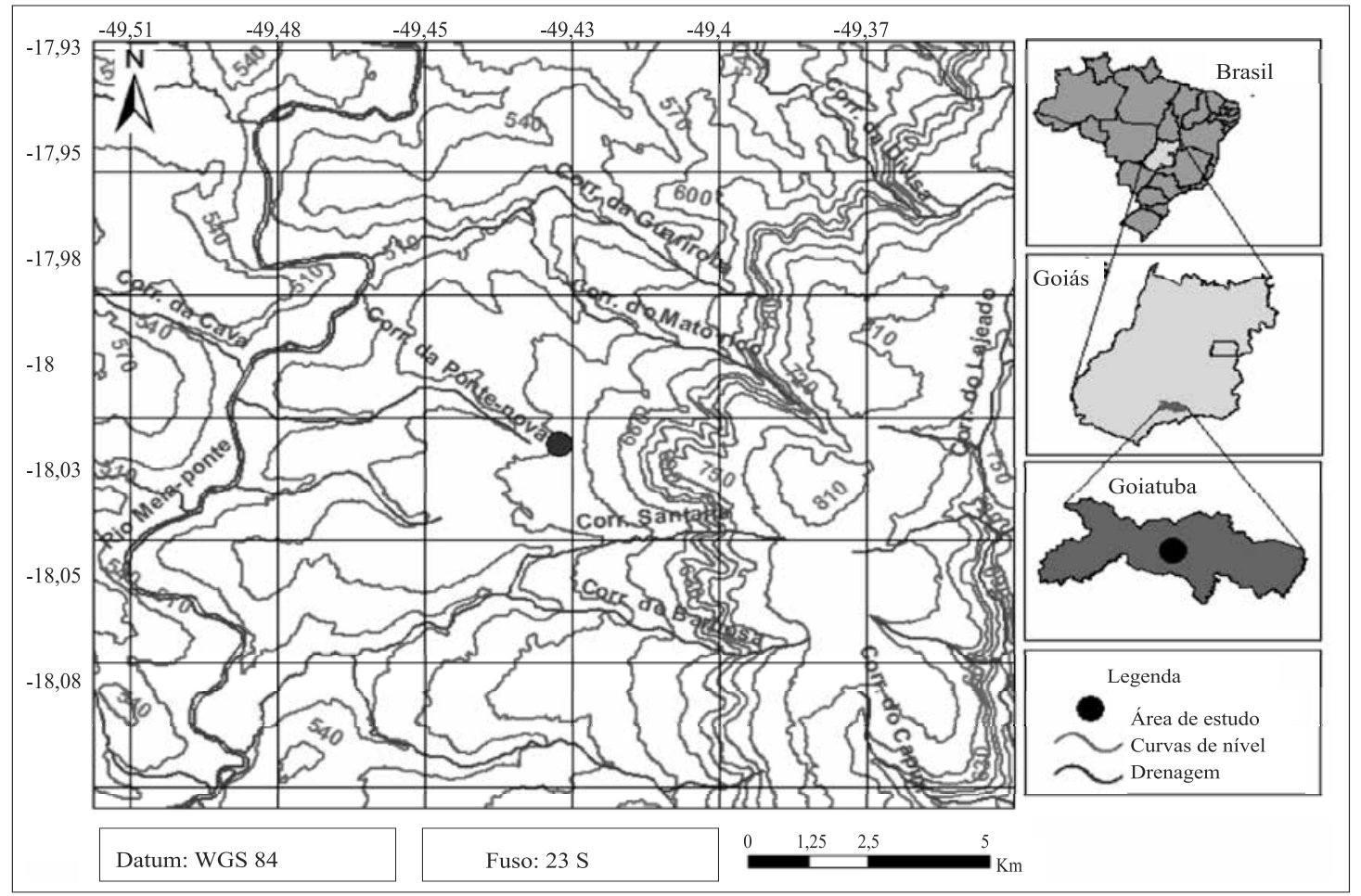

Figura 1. Localização da área de estudo, na cabeceira do Córrego Ponte Nova em Goiatuba, Goiás, Brasil. Crédito: Ricardo de Farias Nicolau.

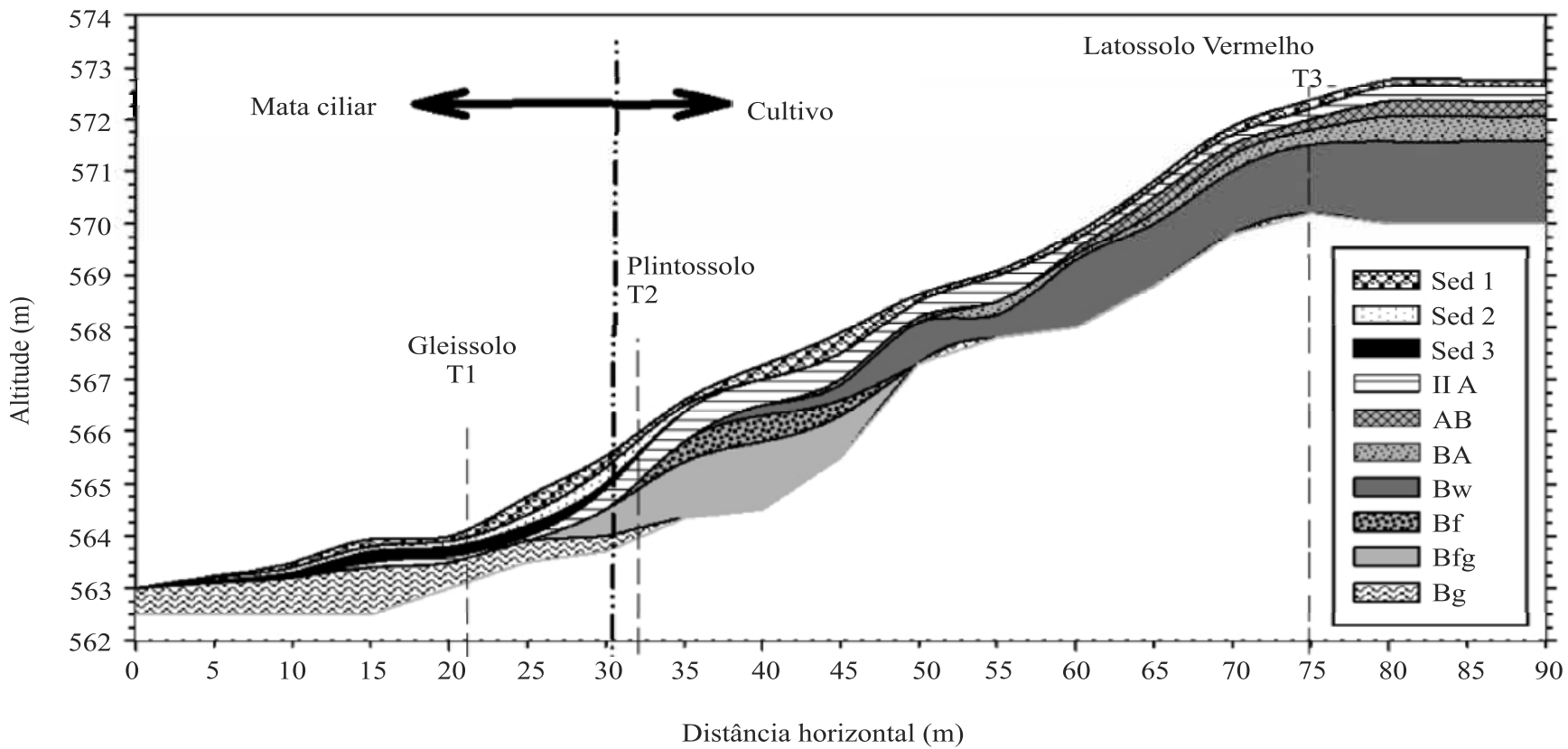

Figura 2. Topossequência de solos numa encosta recoberta por cultivo e mata ciliar nativa de Cerrado. Sed1, sedimentos da camada superficial; Sed2, sedimentos da camada intermediária; Sed3, sedimentos da camada mais profunda; IIA, horizonte A enterrado; $\mathrm{AB}$, horizonte de transição $\mathrm{AB}$; $\mathrm{BA}$, horizonte de transição $\mathrm{BA} ; \mathrm{Bw}-\mathrm{AB}$, horizonte $\mathrm{B}$ latossólico; $\mathrm{Bf}$, horizonte B plíntico; Bf g, horizonte B plíntico gleizado; Bg, horizonte B glei. T3, perfil descrito sob cultivo de soja (Glycine max.) em sistema plantio direto no topo; T2, perfil descrito sob braquiária (Urocloa decumbens) no terço médio; e T1, Perfil descrito sob mata ciliar nativa degradada no sopé. 
As temperaturas médias máximas e mínimas são, respectivamente, 30 e $19^{\circ} \mathrm{C}$.

A vegetação natural da região compreende as fisionomias Cerrado, Cerradão, Mata Seca, Mata de Galeria e Mata Ciliar. Entretanto, por causa do intenso desmatamento e introdução do cultivo de pastagens e soja, as formações florestais originais encontramse degradadas e concentradas nas áreas íngremes das encostas e fundos de vale e nas veredas.

Foram avaliados três perfis de solos: uma topossequência de cultivo de soja (Glycine max) sob sistema de plantio direto no topo, braquiária (Urochloa decumbens) no terço médio e mata ciliar nativa degradada no sopé, no período de outubro de 2008 a abril de 2010 (Figura 2).

Os solos e sedimentos foram descritos morfologicamente e coletados em três perfis, T1, T2 e T3 em transecto numa topossequência (Santos et al., 2005) (Figura 2). A topossequência selecionada representa a paisagem da região, por inserir-se a jusante da extensa escarpa que separa as Superfícies Regionais de Aplainamento II e IV, receber forte influência da ruptura de declive que a escarpa proporciona e conter inúmeras nascentes do Rio Meia Ponte. Além disso, apresenta vegetação original de Cerrado em avançado estágio de degradação, assim como o restante dos fragmentos florestais da região cuja matriz agrícola é dominada por soja. Amostras deformadas foram coletadas para realização de análises físicas e químicas (Donagema et al., 2011) e amostras indeformadas foram coletadas nos solos e sedimentos sob a forma de blocos esculpidos com dimensões de $12 \times 7 \times 5 \mathrm{~cm}$ para avaliação micromorfométrica da porosidade (Cooper et al., 2010; Castilho et al., 2011).

Os solos foram classificados de acordo com o Sistema Brasileiro de Classificação de Solos (Santos et al., 2013), e os dados obtidos possibilitaram a espacialização e distribuição bidimensional dos horizontes dos solos e camadas de sedimentos na topossequência (Boulet, 1982).

Os solos e sedimentos coletados foram analisados quanto à granulometria por meio do método do densímetro adaptado por Camargo et al. (1986). Utilizou-se hexametafosfato de sódio para dispersão total e água para dispersão parcial (ADA - argila dispersa em água) para simular o processo erosivo ocorrido em condições naturais de erosão hídrica via enxurrada (Donagema et al., 2011).
Os poros foram avaliados quanto à quantidade, forma e tamanho por meio da análise microscópica de imagens dos blocos de solo com estrutura preservada (Cooper et al., 2010). A conservação da estrutura foi obtida impregnando os blocos com resina poliéster não saturada, diluída com monômero de estireno acrescida de pigmento fluorescente para distinção dos poros quando iluminados com luz ultravioleta (Silva et al., 2015). Posteriormente à impregnação, secagem e corte, os blocos foram fotografados utilizando-se câmera digital colorida CCD (resolução de $1.024 \times 768$ pixeis e área de $156 \mathrm{~mm}^{2}$ pixel $^{-1}$ ). O processamento das imagens adquiridas foi realizado utilizando-se o programa de análise de imagens Noesis Visilog, por meio do qual foi determinada a porosidade total baseada na proporção da área da imagem ocupada por poros (PAI, "pore area by image") (Souza et al., 2006), e os poros foram separados em diferentes classes de tamanho: pequenos $\left(1,56 \times 10^{-4}\right.$ a $\left.1,56 \times 10^{-2} \mathrm{~mm}^{2}\right)$; médios $\left(1,56 \times 10^{-2}\right.$ e 0,156 $\mathrm{mm}^{2}$ ) e grandes, com áreas maiores do que $0,156 \mathrm{~mm}^{2}$; e separados também por forma: arredondado, alongado e complexos (Silva et al., 2015).

\section{Resultados e Discussão}

Os solos identificados na topossequência soja-mata ciliar do Córrego Ponte Nova são essencialmente argilosos e avermelhados, assim como os sedimentos depositados na superfície (Tabela 1). O levantamento pedológico detalhado sob a forma de transecto evidenciou a variação lateral dos solos e a classificação indicou a ocorrência de Latossolo Vermelho distroférrico (LVdf) argiloso no terço superior da encosta (T3), de Plintossolo Pétrico Concrecionário êutrico (FFc) argiloso no terço inferior da encosta (T2), e de Gleissolo Melânico Tb distrófico típico (GMbd) argiloso na baixada (T1) (Figura 2).

O LVdf presente no terço superior da topossequência vem sendo submetido ao cultivo de soja desde 1985. A partir de 1995 foi adotado o sistema de plantio direto, entretanto a cobertura vegetal de palhada sobre o solo não representa proteção suficiente contra os efeitos da erosão. Sobre o FFc do terço médio onde situa-se a borda da mata ciliar desenvolve-se vegetação nativa de cerrado simultaneamente $\mathrm{e}, \mathrm{em}$ meio à plantas invasoras como mamona (Ricinus communis L.) e gramíneas. Sobre o GMbd, no terço inferior da topossequência, desenvolve-se vegetação ciliar típica de vereda, com presença de Buritis (Mauritia flexuosa) e árvores de 
médio a grande porte, com vegetação reduzida de sub-bosque, indicando forte degradação do fragmento.

O Latossolo Vermelho é homogêneo, avermelhado e profundo com variações estruturais de grau e tamanho. Sobre seu horizonte A superficial, foi encontrada apenas uma camada de sedimentos depositados. Não foi observada presença de cerosidade em nenhum dos perfis analisados e a atração magnética variou de moderada a muito forte de T1 para T3.

O Plintossolo Pétrico apresentou-se profundo e heterogêneo, localizado na borda da mata ciliar limítrofe à área cultivada. Apresenta cores avermelhadas e duas camadas de sedimentos depositados sobre o horizonte A enterrado. Nódulos de ferro foram observados no depósito inferior de sedimentos e em profundidade, entre $0,80 \mathrm{~m}$ e $1,20 \mathrm{~m}$.

O Gleissolo Melânico apresentou cores avermelhadas escurecidas pela matéria orgânica proveniente da cobertura florestal da mata ciliar e alta umidade a partir de $0,10 \mathrm{~m}$ de profundidade. É um solo pouco profundo e, a partir de $0,38 \mathrm{~m}$ de profundidade, predominam condições de saturação hídrica na estação seca. A presença de lençol freático aflorando à superfície imprime condições de hidromorfia que resultam na presença de horizonte glei subjacente a um horizonte superficial orgânico. Sobre estes horizontes, foi constatada a presença de três diferentes camadas de sedimentos com variações estruturais de grau, tipo e tamanho, além de variações de espessura e coloração.

As análises granulométricas identificaram solos e sedimentos argilosos, com presença mediana de fração areia e mínima de silte. Tal distribuição ocorre de forma homogênea tanto em profundidade quanto lateralmente na encosta sobre os solos derivados do intemperismo de rochas ricas em minerais ferro-magnesianos, como basalto/diabásio, da Formação Serra Geral (Ker, 1997; Galinkin, 2003; Lacerda \& Barbosa, 2012). Resultados similares foram observados em solos do Planalto Central Goiano, onde solos profundos e argilosos apresentaram distribuição espacial semelhante à verificada neste estudo, com a presença de Latossolos nos topos aplainados variando lateralmente para Plintossolos em condições de hidromorfia (Motta et al., 2002).

Tabela 1. Atributos morfológicos dos solos e sedimentos nas três posições da encosta avaliada. Sed1, Sedimento da camada 1; Sed2, Sedimento da camada 2; Sed3, Sedimento da camada 3; IIA, Horizonte A enterrado; A/B, Horizonte de transição A/B; B/A, Horizonte de transição B/A; Bw, Horizonte B latossólico; Bf, Horizonte B plíntico; Bfg, Horizonte B plíntico gleissólico; Bg, Horizonte B gleissólico.

\begin{tabular}{|c|c|c|c|c|c|c|}
\hline \multirow[t]{2}{*}{ Horizonte } & \multirow{2}{*}{$\begin{array}{l}\text { Profundidade } \\
\text { (m) }\end{array}$} & \multicolumn{2}{|c|}{ Cor (Munsell) } & \multirow[t]{2}{*}{ Estrutura } & \multirow[t]{2}{*}{ Textura } & \multirow{2}{*}{$\begin{array}{c}\text { Atração } \\
\text { magnética }\end{array}$} \\
\hline & & Seca & Úmida & & & \\
\hline & & & & Perfil T1, Baixada/Mata Ciliar (interior) & & \\
\hline Sedimento & $0-0,09$ & $2,5 \mathrm{YR} 3 / 2$ & $10 \mathrm{R} 3 / 2$ & Grau fraco, granular a blocos subangulares pequenos & Argilosa & Moderada \\
\hline Sedimento & $0,09-0,2$ & $2,5 \mathrm{YR} 3 / 4$ & $10 \mathrm{R} 3 / 2$ & Grau fraco, maciça a blocos subangulares, pequenos & Argilosa & Moderada \\
\hline Sedimento & $0,2-0,38$ & $2,5 \mathrm{YR} 3 / 4$ & $10 \mathrm{R} 3 / 3$ & Grau fraco a moderado, maciça a blocos subangulares grandes & Argilosa & Moderada \\
\hline IIA & $0,38-0,5$ & $2,5 \mathrm{YR} 3 / 4$ & $10 \mathrm{R} 3 / 3$ & Grau moderado, blocos subangulares médios & Argilosa & Moderada \\
\hline \multirow[t]{2}{*}{$\underline{\mathrm{Bg}}$} & $0,5+$ & $2,5 \mathrm{YR} 5 / 2$ & $10 \mathrm{R} 5 / 2$ & Grau moderado, blocos subangulares médios & Argilosa & Moderada \\
\hline & & & & Perfil T2, Terço inferior/Mata Ciliar (borda)/Cultivo & & \\
\hline Sedimento & $0-0,1$ & $2,5 \mathrm{YR} \mathrm{3/6}$ & $2,5 \mathrm{YR} 3 / 4$ & Grau fraco a moderado, granular a blocos subangulares pequenos & Muito argilosa & Forte \\
\hline Sedimento & $0,1-0,22$ & $2,5 \mathrm{YR} \mathrm{3/6}$ & $2,5 \mathrm{YR} 3 / 4$ & Grau moderado a forte, granular, pequenos & $\begin{array}{l}\text { Argilosa / } \\
\text { cascalhenta }\end{array}$ & Forte \\
\hline IIA & $0,22-0,8$ & $2,5 \mathrm{YR} 3 / 6$ & $2,5 \mathrm{YR} 3 / 4$ & Grau moderado, blocos subangulares pequeno a médios & Argilosa & Muito forte \\
\hline $\mathrm{Bf}$ & $0,8-1,18$ & $2,5 \mathrm{YR} 3 / 4$ & $10 \mathrm{R} 3 / 3$ & Grau moderado, blocos subangulares, pequenos a médios & $\begin{array}{l}\text { Argilosa / } \\
\text { cascalhenta }\end{array}$ & Muito forte \\
\hline \multirow[t]{2}{*}{ Bfg } & $1,18+$ & $2,5 \mathrm{YR} 3 / 2$ & $10 \mathrm{R} 3 / 2$ & Grau moderado, blocos subangulares, pequenos a médios & Argilosa & Muito forte \\
\hline & & & & Perfil T3, Terço superior/Cultivo & & \\
\hline Sedimento & $0-0,12$ & $2,5 \mathrm{YR} 3 / 4$ & $10 \mathrm{R} 2,5 / 2$ & Grau moderado a forte, blocos subangulares, pequenos & Argilosa & Forte \\
\hline IIA & $0,12-0,42$ & $2,5 \mathrm{YR} 3 / 4$ & $10 \mathrm{R} 3 / 3$ & Grau fraco a moderado, blocos angulares, pequenos & Muito argilosa & Muito forte \\
\hline $\mathrm{A} / \mathrm{B}$ & $0,42-0,7$ & $2,5 \mathrm{YR} \mathrm{3/6}$ & $10 \mathrm{R} 3 / 3$ & Grau moderado, blocos subangulares, pequenos a médios & Argilosa & Muito forte \\
\hline $\mathrm{B} / \mathrm{A}$ & $0,7-1,20$ & $2,5 \mathrm{YR} 3 / 4$ & $10 \mathrm{R} 3 / 2$ & Grau moderado, blocos subangulares a angulares, médios & Argilosa & Muito forte \\
\hline$\underline{\mathrm{Bw}}$ & $1,20+$ & $2,5 \mathrm{YR} 3 / 6$ & $10 \mathrm{R} 3 / 3$ & Grau moderado, blocos subangulares a angulares, médios a grandes & Argilosa & Muito forte \\
\hline
\end{tabular}


Sobre todos os solos analisados, foi identificada a presença de sedimentos argilosos e avermelhados (Tabela 1). A presença de sedimentos depositados ao longo da encosta, principalmente sobre GMbd e FFc, confirma a ocorrência de processos erosivos a montante, onde oLVdf vem apresentando perda de solo, assim como averiguado em Latossolo Vermelho distrófico típico cultivado no Cerrado mato-grossense, que apresentou perdas de solo de até $4,87 \mathrm{Mg} \mathrm{ha}^{-1}$ ano $^{-1}$ (Cândido et al., 2014). Experimento conduzido em Latossolo Vermelho no Cerrado mineiro, cultivado sob clima tropical quente e úmido com chuvas de erosividade média de 9.000 MJ mm ha ${ }^{-1} \mathrm{~h}^{-1}$ ano $^{-1}$, constatou perdas de solo da ordem de $14 \mathrm{Mg} \mathrm{ha}^{-1}$ ano $^{-1}$ (Silva et al., 2005). Expressivas perdas de solo podem ocorrer até mesmo em Latossolos, solos considerados estáveis, mas que, quando submetidos a manejo inadequado, sofrem forte desestabilização e ficam vulneráveis à remoção e transporte de partículas de argila.

A adoção de plantio direto como única medida de conservação do solo no Cerrado consiste em manejo inadequado. As condições edafoclimáticas da região, principalmente a seca prolongada, consistem em limitações para o pleno desenvolvimento de plantas de cobertura, produção e acúmulo de biomassa (Carvalho, 2010). O deficiente acúmulo de biomassa ou palhada sobre a superfície resulta na ausência de cobertura do solo e favorecimento da ocorrência de erosão hídrica.

De acordo com Ker (1997), os Latossolos ocupam $46 \%$ da área total do Cerrado, constituem a classe mais explorada economicamente pela agricultura, são submetidos a até duas safras/ano e vêm apresentando severos danos relativos à perda de solo. Neste cenário, de relevante participação espacial e econômica, recomenda-se urgência na adoção de medidas de proteção, conservação e incremento da qualidade dos Latossolos.

A análise granulométrica confirmou a inspeção de campo quanto à predominância de solos argilosos e homogêneos. Foram verificados teores médios de 550 $\mathrm{g} \mathrm{kg}^{-1}$ para argila, $300 \mathrm{~g} \mathrm{~kg}^{-1}$ para areia e $150 \mathrm{~g} \mathrm{~kg}^{-1}$ para silte, tanto nos solos quanto nos sedimentos.

Observa-se uma tendência à homogeneidade textural nos solos tanto em profundidade quanto ao longo da encosta, indicando similaridade vertical e horizontal. A textura dos sedimentos variou de argilosa a muito argilosa, indicando similaridade com a fonte de sedimentos. O horizonte Bw do LVdf contém maior proporção de grãos tamanho areia, provavelmente devido à concentração de petroplintita ou de minerais como quartzo proveniente do basalto vesicular da região. Elevada participação da fração areia também foi verificada no horizonte $\mathrm{Bf}$ do $\mathrm{FFc}$ e pode ser atribuída à maior proporção de concreções nodulares de ferro. Moreira \& Oliveira (2008) identificaram em Plintossolo Pétrico concrecionário da região de Ouro Verde, no Estado de Goiás, a predominância de quartzo na constituição mineralógica da fração areia, atribuída ao material de origem e também ao acúmulo de partículas grandes e pesadas transportadas ao longo das encostas e depositadas nas posições rebaixadas da paisagem.

A comparação entre a dispersão dos solos e sedimentos em hexametafosfato de sódio e em água dos solos e sedimentos indicou que mais de $90 \%$ da fração argila se agrega como grãos de tamanho silte ou areia em todos os solos e sedimentos avaliados (Figura 3).

A alta taxa de agregação dos solos está relacionada, prioritariamente, à presença de agentes cimentantes, como óxidos de ferro herdados do material de origem, e, secundariamente, à atração elétrica entre as partículas unitárias devido à natureza mineralógica da fração argila. Estudo sobre produção de sedimentos em Latossolos verificou a ocorrência de agregados de argila de maior diâmetro em Latossolo Vermelho aluminoférrico (LVaf) e Latossolo Vermelho distroférrico (LVdf) em comparação ao Latossolo Vermelho distrófico (LVd) (Nunes \& Cassol, 2011). A ação cimentante dos óxidos de ferro e alumínio presentes nos LVaf e LVdf contribui para a elevada coesão entre as partículas, o que favorece a estabilidade desses solos. Entretanto, a susceptibilidade à erosão pode ser favorecida sob condições de fluxo hídrico intenso, posição de maior declividade na encosta e ausência de cobertura do solo. Sob tais condições, os agregados de argila se dispersam em água podendo se deslocar e ser removidos facilmente encosta abaixo.

No GMbd, de forma geral, houve maior incremento de agregados tamanho areia nos horizontes subsuperficiais, enquanto no FFc e no LVdf houve maior incremento de agregados de tamanho silte. A predominância de agregados de tamanho silte no LVdf é particularmente preocupante, visto que seu diminuto tamanho facilita o transporte durante a enxurrada, conforme relatado por Cândido et al. (2014). Além 
disso, ocupando posições elevadas tanto na encosta quanto no perfil, é facilmente removido e transportado encosta abaixo. Ma et al. (2014) relataram o transporte de agregados de tamanhos entre 0,25 e $0,5 \mathrm{~mm}$ e 0,5 e $1,0 \mathrm{~mm}$ por salpicamento provocado pelas gotas de chuva.

Os sedimentos do FFc e do LVdf possuem maior concentração de agregados de tamanho areia do que os respectivos solos. Essa concentração decorre do acúmulo de agregados maiores, enquanto os agregados de tamanho silte e a argila continuam a ser transportados até os cursos d'água. Estudo sobre erosão em Latossolo Vermelho distrófico textura média no Cerrado constatou a presença de maiores teores de areia do que argila na camada superior do solo na ocorrência de selamento superficial (Cândido et al., 2014). A maior percentagem de argila dispersa em todos os horizontes do GMbd demonstra menor atuação das forças de agregação/coesão no ambiente saturado em relação aos solos mais secos a montante.

A elevada participação de agregados do tamanho areia e silte $(>90 \%)$, até mesmo em profundidade, evidencia a tendência natural de forte agregação das partículas de argila. A elevada coesão possibilita que os agregados sejam transportados sem rompimento, resultando em sedimentos de tamanhos semelhantes apesar da incidência comum na região de chuvas intensas acima de $60 \mathrm{~mm} \mathrm{~h}^{-1}$. A remoção seletiva de materiais finos também poderia estar ocorrendo. Entretanto, o inexpressivo teor de argila particulada em subsuperfície sugere que a participação dessa fração é irrelevante no processo erosivo.

A micromorfometria indicou valores elevados de porosidade total $(\mathrm{Pt})$ para os macro e mesoporos dos sedimentos superficiais (Sed1) depositados sobre solos sob a mata ciliar comparados aos depositados sobre o solo cultivado (Figura 4). A Pt apresentou gradual redução em profundidade nos solos GMbd e FFc e aumento em profundidade no LVdf.

Nota-se a tendência de menor porosidade total Pt nos horizontes com maior proporção de agregados de tamanho silte, como o IIA em todos os perfis e o $\mathrm{Bf}$ e Bfg do FFc. Estes horizontes apresentam menor contribuição relativa dos poros complexos e maior participação de poros arredondados e alongados. Apesar da presença de poros alongados de tamanho
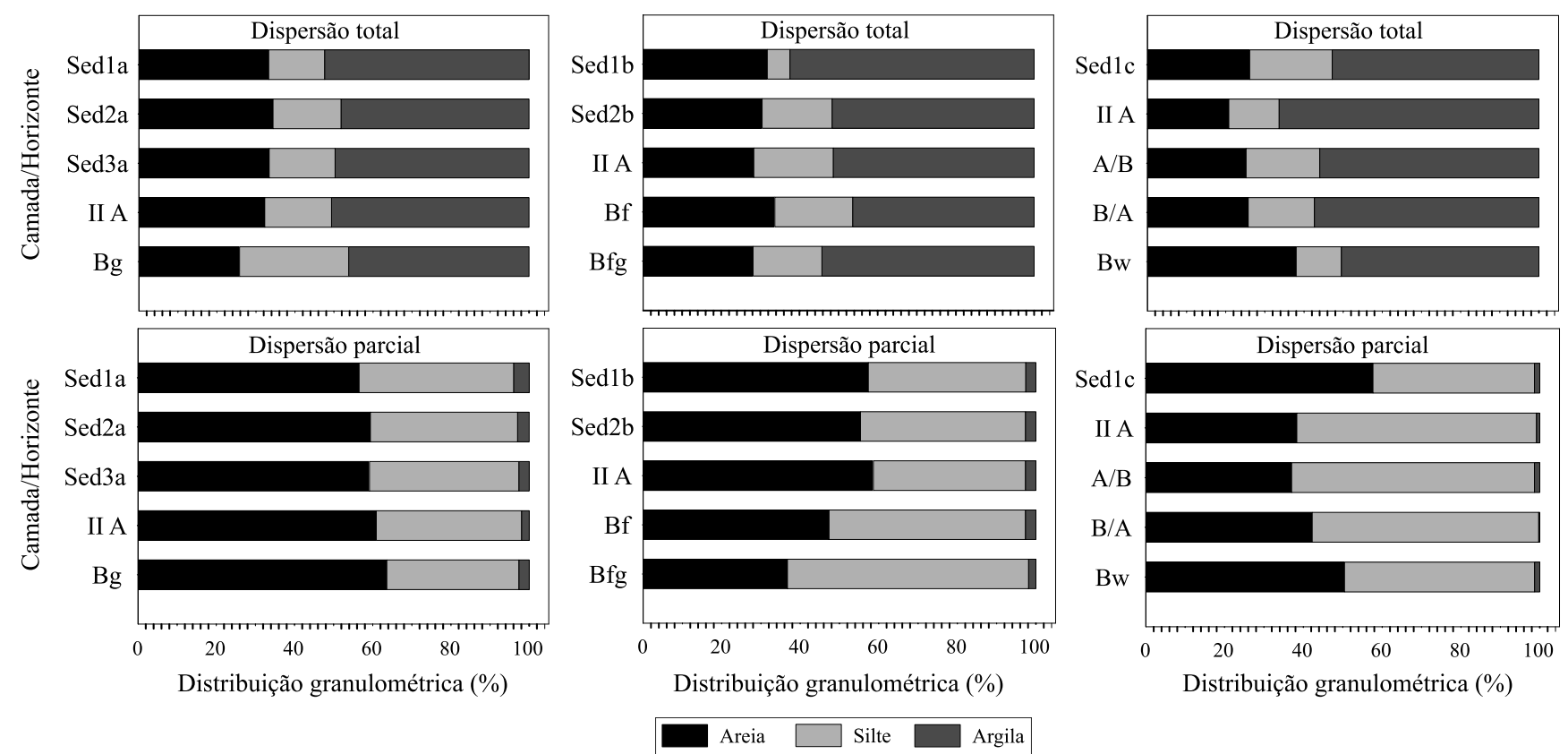

Figura 3. Distribuições granulométricas total com hexametafosfato e parcial com água dos horizontes e das camadas dos solos avaliados descritos na Tabela 1. 

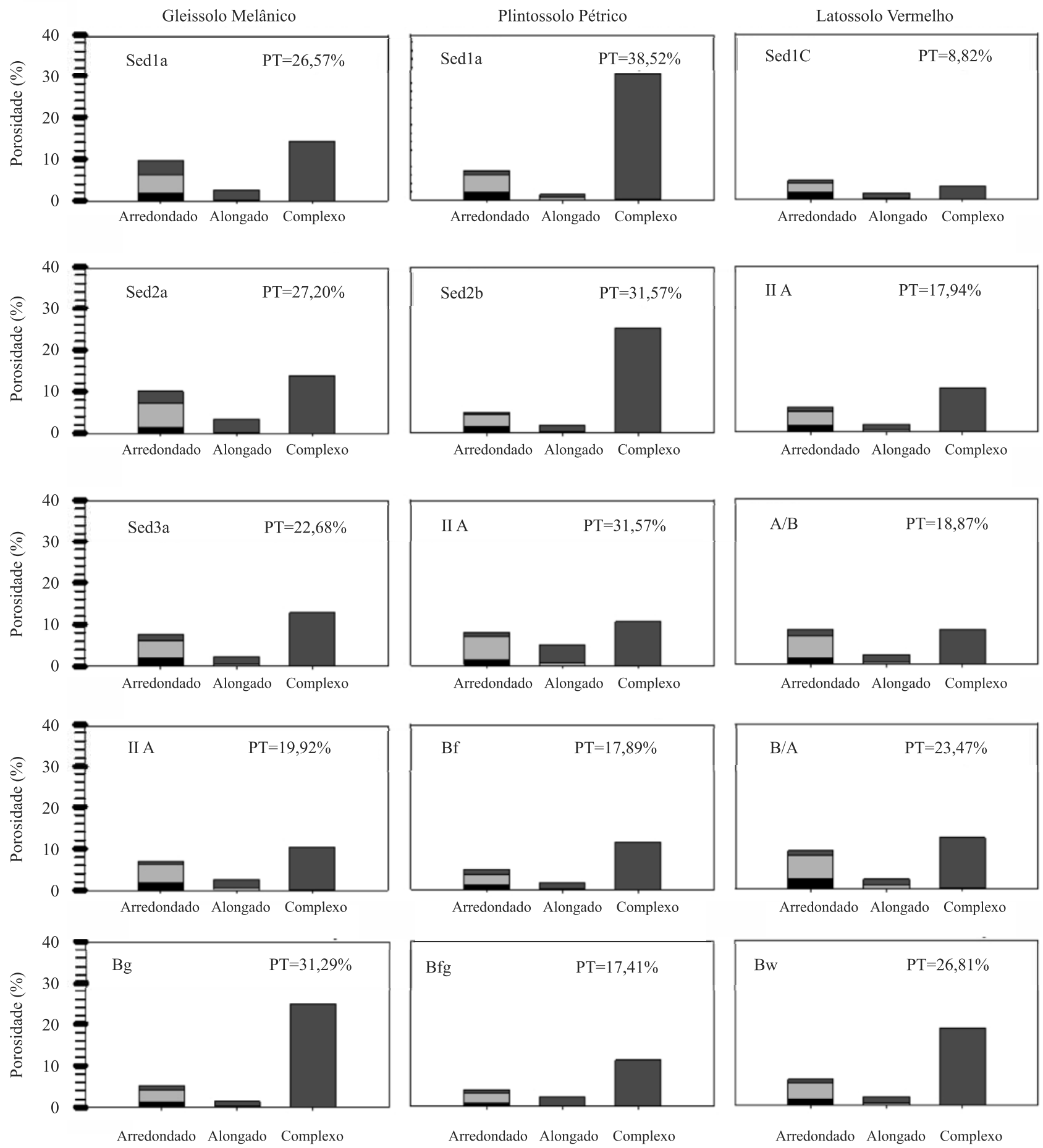

Pequeno $\square$ Médio $\square$ Grande

Figura 4. Aspectos micromorfométricos de proporção, tamanho e forma da porosidade total (PT) dos solos e sedimentos (Sed) descritos na Tabela 1. 
grande, o predomínio de poros arredondados prejudica a infiltração da água no solo pela ausência de conexão entre os poros.

No GMbd e FFc, os sedimentos apresentam alta Pt e maior proporção de poros grandes e complexos, refletindo elevada atividade biológica nos solos não cultivados. Já o LVdf cultivado apresenta baixa Pt e baixa proporção de macro e mesoporosidade em superfície e em subsuperfície, além de evidências de selamento superficial. Esses aspectos são indicadores de solos compactados, com reduzida atividade biológica e alto potencial de perda de solo por erosão.

A porosidade calculada para um Latossolo distrófico no Paraná sob mata nativa foi maior do que em solos sob cultivo, sendo que a porosidade total reduziu de 30 para $0,07 \%$. Operações de cultivos sucessivas, que consistiam de seis passagens de trator sobre Latossolo Vermelho, diminuíram a macroporosidade de 16 para $7 \%$, com as maiores reduções tendo ocorrido próximo à superfície (Freddi et al., 2009).

Camadas compactadas por tráfego de máquinas e implementos agrícolas apresentaram alterações hidráulicas de infiltração de um Latossolo Vermelho que provocaram a formação de sulcos de erosão e grande perda de solo (Thomaz, 2013). A infiltração prejudicada provoca favorecimento do escoamento superficial e consequentemente promove a erosão.

A porosidade no FFC, solo da borda da mata ciliar, mais seco apresenta maior proporção de poros complexos e menor presença de poros arredondados, refletindo a presença de bioporos resultante da atividade biológica. No GM, apesar da elevada atividade biológica e aporte de matéria orgânica pela mata, a porosidade conectada ou complexa é reduzida, predominando poros arredondados pequenos, médios e grandes. Essa redução na porosidade pode decorrer do colapso dos poros conectados por causa do peso dos sedimentos aportados após a erosão ou relacionado às oscilações sazonais do lençol freático.

A compactação e selamento superficial que impactaram negativamente o LVdf cultivado afetaram expressivamente também GM e FFC da mata ciliar, pois os sedimentos se acumularam sobre os solos saturados assoreando a vereda, prejudicando a aeração e o pleno desenvolvimento da biota.

\section{Conclusões}

1. Os parâmetros morfológicos, granulométrico e de porosidade por micromorfometria de imagens foram adequados para identificar o uso e manejo do solo como fator desencadeante da erosão no Latossolo Vermelho distroférrico (LVdf), com consequente deposição de sedimentos sobre Plintossolo Pétrico (FFc) e Gleissolo Melânico (GM).

2. O LVdf argiloso e recoberto por fina camada de sedimentos, constituída de agregados de argila de tamanho areia e silte, apresenta porosidade reduzida na superfície e em subsuperfície, compatível com operações mecanizadas de cultivo de soja em solos argilosos.

3. Os solos da mata ciliar, FFc e GM foram afetados pela erosão do LVdf da encosta à montante, pelo acúmulo de espessas camadas de sedimentos argilosos, os quais apresentaram porosidade elevada, relacionada à atividade biológica e à porosidade de empilhamento dos agregados de tamanho areia e silte.

4. As espessas camadas de sedimentos provenientes da erosão no LVdf depositadas sobre o GM, na área úmida que contém a mata ciliar e nascentes do Córrego Ponte Nova, constituem expressivo impacto à qualidade do solo, com comprometimento de sua função ecológica e de filtro.

5. Os sedimentos provenientes da erosão a montante provocam soterramento de sementes e plântulas, e dificultam a germinação e o estabelecimento de plantas nativas.

\section{Agradecimentos}

Ao Conselho Nacional de Desenvolvimento Científico e Tecnológico (CNPq), pelo financiamento e bolsas concedidas; ao Programa de Pós-Graduação em Solos e Nutrição de Plantas Escola Superior de Agricultura Luiz de Queiroz (Esalq/USP), pela viabilização das coletas, análises de laboratório e apoio logístico.

\section{Referências}

BOULET, R.; CHAUVEL, A.; HUMBEL, F.-X.; LUCAS, Y. Analyse structurale et cartographie en pédologie: I - Prise en compte de l'organisation bidimensionelle de La couverture pédologique: les études de toposéquences et leurs principaux apports à La connaissance dês sols. Cahiers ORSTOM: Série Pédologie, v.19, p.309-321, 1982.

Pesq. agropec. bras., Brasília, v.51, n.9, p.1295-1305, set. 2016 DOI: 10.1590/S0100-204X2016000900029 
CAMARGO, O.A. de; MONIZ, A.C.; JORGE, J.A.; VALADARES, J.M.A.S. Métodos de análise química, mineralógica e física de solos do Instituto Agronômico de Campinas. Campinas: IAC, 1986. 94p. (IAC. Boletim técnico, 106).

CÂNDIDO, B.M.; SILVA, M.L.N.; CURI, N.; BATISTA, P.V.G. Erosão hídrica pós-plantio em florestas de eucalipto na bacia do rio Paraná, no leste do Mato Grosso do Sul. Revista Brasileira de Ciência do Solo, v.38, p.1565-1575, 2014. DOI: 10.1590/S010006832014000500022.

CARVALHO, A.M. de. Plantio direto com qualidade no cerrado. Planaltina: Embrapa Cerrados, 2010. Disponível: <http://www. cpac.embrapa.br/noticias/artigosmidia/publicados/242>. Acesso em: 25 out. 2010 .

CARVALHO, R.; SILVA, M.L.N.; AVANZI, J.C.; CURI, N.; SOUZA, F.S. de. Erosão hídrica em Latossolo Vermelho sob diversos sistemas de manejo do cafeeiro no Sul de Minas Gerais. Ciência e Agrotecnologia, v.31, p.1679-1687, 2007. DOI: 10.1590/S1413-70542007000600012.

CASTILHO, S.C. de P.; COOPER, M.; JUHÁSZ, C.E.P. Influence of crust formation under natural rain on physical attributes of soils with different textures. Revista Brasileira de Ciência do Solo, v.35, p.1893-1905, 2011. DOI: 10.1590/S0100-06832011000600006.

COOPER, M.; VIDAL-TORRADO, P.; GRIMALDI, M. Soil structure transformations from ferralic to nitic horizons on a toposequence in Southeastern Brazil. Revista Brasileira de Ciência do Solo, v.34, p.1685-1669, 2010. DOI: 10.1590/S010006832010000500021.

DONAGEMA, G.K.; CAMPOS, D.V.B. de; CALDERANO, S.B.; TEIXEIRA, W.G.; VIANA, J.H.M. (Org.). Manual de métodos de análise de solo. 2.ed. rev. Rio de Janeiro: Embrapa Solos, 2011. 230p. (Embrapa Solos. Documentos, 132).

FREDDI, O. da S.; CENTURION, J.F.; DUARTE, A.P.; LEONEL, C.L. Compactação do solo e produção de cultivares de milho em Latossolo Vermelho. I - Características de planta, solo e índice $S$. Revista Brasileira de Ciências do Solo, v.33, p.793-803, 2009. DOI: 10.1590/S0100-06832009000400005.

GALINKIN, M. GeoGoiás 2002. Goiânia: Agência Ambiental de Goiás, 2003. 272p.

KER, J.C. Latossolos do Brasil: uma revisão. Geonomos, v.5, p.17-40, 1997.

LACERDA, M.P.C.; BARBOSA, I.O. Relações pedomorfogeológicas e distribuição de pedoformas na Estação Ecológica de Águas Emendadas, Distrito Federal. Revista Brasileira de Ciência do Solo, v.36, p.709-721, 2012. DOI: 10.1590/S0100-06832012000300003.

LAL, R. Soil conservation and ecosystem services. International Soil and Water Conservation Research, v.2, p.36-47, 2014. DOI: 10.1016/S2095-6339(15)30021-6.

LATRUBESSE, E.M.; CARVALHO, T.M. de. Geomorfologia do Estado de Goiás e Distrito Federal. Goiânia: Secretaria de Indústria e Comércio de Goiás, 2006. 128p. (Superintendência de Geologia e Mineração. Série geologia e mineração, 2).

MA, R.M.; LI, Z.X.; CAI, C.F.; WANG, J.G. The dynamic response of splash erosion to aggregate mechanical breakdown through rainfall simulation events in Ultisols (subtropical China). Catena, v.121, p.279-287, 2014. DOI: 10.1016/j.catena.2014.05.028.

MOMOLI, R.S.; COOPER, M.; TOMAZELLO FILHO, M.; LOBÃO, M.S. Aplicação da dendrogeomorfologia no estudo da deposição de sedimentos do solo no tronco de árvores de Guarea guidonea em mata ciliar antropizada no Estado de Goiás, Brasil. Scientia Forestalis, v.40, p.7-14, 2012.

MOREIRA, H.L.; OLIVEIRA, V.A. de. Evolução e gênese de um Plintossolo Pétrico concrecionário êutrico argissólico no município de Ouro Verde de Goiás. Revista Brasileira de Ciência do Solo, v.32, p.1683-1690, 2008. DOI: 10.1590/S010006832008000400033.

MOTTA, P.E.F. da; CARVALHO FILHO A. de; KER, J.C.; PEREIRA, N.R.; CARVALHO JUNIOR, W. de; BLANCANEAUX, P. Relações solo-superfície geomórfica e evolução da paisagem em uma área do Planalto Central Brasileiro. Pesquisa Agropecuária Brasileira, v.37, p.869-878, 2002. DOI: 10.1590/S0100204X2002000600017.

NUNES, M.C.M.; CASSOL, E.A. Produção de sedimentos pela erosão em entressulcos em três Latossolos do Rio Grande do Sul. Revista Brasileira de Engenharia Agrícola e Ambiental, v.15, p.541-547, 2011. DOI: 10.1590/S1415-43662011000600001.

OLIVETTI, D.; MINCATO, R.L.; AYER, J.E.B.; SILVA, M.L.N.; CURI, N. Spatial and temporal modeling of water erosion in dystrophic Red Latosol (oxisol) used for farming and cattle raising activities in a sub-basin in the South of Minas Gerais. Ciência e Agrotecnologia, v.39, p.58-67, 2015. DOI: 10.1590/S141370542015000100007.

SANTOS, H.G. dos; JACOMINE, P.K.T.; ANJOS, L.H.C.; OLIVEIRA, V.A. de; LUMBRERAS, J.F.; COELHO, M.R.; ALMEIDA, J.A. de; CUNHA, T.J.F.; OLIVEIRA, J.B. de. Sistema brasileiro de classificação de solos. 3.ed. rev. e ampl. Brasília: Embrapa, 2013. 353p.

SANTOS, R.D. dos; LEMOS, R.C. de; SANTOS, H.G. dos; KER, J.C.; ANJOS, L.H.C. dos. Manual de descrição e coleta de solos no campo. 5.ed. Viçosa: Sociedade Brasileira de Ciência do Solo, 2005. 92p.

SIEFERT, C.A.C.; SANTOS, I. dos. Mecanismo de geração de escoamento e áreas hidrologicamente sensíveis: uma abordagem hidrogeomorfológica para delimitação de áreas de preservação permanente. RA'E GA: o Espaço Geográfico em Análise, v.24, p.227-257, 2012.

SILVA, A.M.; SILVA, M.L.N.; CURI, N.; LIMA, J.M. Perdas de solo, água, nutrientes e carbono orgânico em Cambissolo e Latossolo sob chuva natural. Pesquisa Agropecuária Brasileira, v.40, p.1223-1230, 2005. DOI: 10.1590/S0100204X2005001200010.

SILVA, L.F.S. da; MARINHO, M. de A.; MATSURA, E.E.; COOPER, M.; RALISCH, R. Morphological and micromorphological changes in the structure of a Rhodic Hapludox as a result of agricultural management. Revista Brasileira de Ciência do Solo, v.39, p.205-221, 2015. DOI: 10.1590/01000683rbcs20150045.

SOUZA, Z.M. de; MARQUES JÚNIOR, J.; COOPER, M.; PEREIRA, E.G.T. Micromorfologia do solo e sua relação 
com atributos físicos e hídricos. Pesquisa Agropecuária Brasileira, v.41, p.487-492, 2006. DOI: 10.1590/S0100204X2006000300016.

TELlES, T.S.; GUIMARÃES, M. de F.; DECHEN, S.C.F. The costs of soil erosion. Revista Brasileira de Ciência do Solo, v.35, p.287-298, 2011. DOI: 10.1590/S010006832011000200001 .

THOMAZ, E.L. Rill erosion on an oxisol influenced by a thin compacted layer. Revista Brasileira de Ciência do Solo, v.37, p.1383-1392, 2013. DOI: 10.1590/S0100-06832013000500027.

Recebido em 28 de agosto de 2015 e aprovado em 24 de novembro de 2015 